\title{
Bedtime administration of antihypertensive medication can reduce morning blood pressure surges in hypertensive patients: a systematic review and meta-analysis
}

\author{
Haiyan Jiang, Zhun Yu, Jimin Liu, Wei Zhang \\ The Third Affiliated Hospital of the Changchun University of Chinese Medicine, Changchun, China \\ Contributions: (I) Conception and design: H Jiang, W Zhang; (II) Administrative support: Z Yu; (III) Provision of study materials or patients: J Liu; \\ (IV) Collection and assembly of data: H Jiang; (V) Data analysis and interpretation: H Jiang, Z Yu; (VI) Manuscript writing: All authors; (VII) Final \\ approval of manuscript: All authors. \\ Correspondence to: Wei Zhang. Department of Orthopedics, The Third Affiliated Hospital of the Changchun University of Chinese Medicine, \\ Changchun, China. Email: wei19830403@163.com.
}

\begin{abstract}
Background: The risk of cardiovascular and cerebrovascular events is the highest during the first several hours post-awakening in patients with hypertension. This is largely due to surges in morning blood pressure (BP). The current meta-analysis explored whether morning BP is affected by the timing of antihypertensive drug administration.

Methods: Four medical databases were searched for clinical trials that examined the relationship between the timing of antihypertensive drug administration and morning BP levels. This meta-analysis compared morning BP surges in patients administered medication at bedtime versus patients administered medication during the day.

Results: The random effects model demonstrated that bedtime administration of antihypertensive drugs reduced morning systolic blood pressure (SBP) by $1.17 \mathrm{mmHg}$ [with $95 \%$ confidence interval (CI): -2.47 to 0.37; $\mathrm{P}=0.08$ ), and reduced morning diastolic blood pressure (DBP) by $0.95 \mathrm{mmHg}$ (95\% CI: -2.03 to 0.13 ; $\mathrm{P}=0.08$ ), compared with patients who were administered medication during the daytime hours. However, the results did not demonstrate statistical significance. There was strong heterogeneity in both morning SBP $\left(\mathrm{I}^{2}\right.$ $=77.9 \%>50 \%$, and $\mathrm{Q}$ test $>0.1)$ and morning DBP results $\left(\mathrm{I}^{2}=77.9 \%>50 \%\right.$, and $\mathrm{Q}$ test $\left.>0.1\right)$. The funnel plots showed no publication bias in this study.

Discussion: Studies have shown that a $1 \mathrm{mmHg}$ change was sufficient to reduce the risk of cardiovascularrelated deaths by $2.1 \%$. Therefore, changing the time of taking antihypertensive medications may significantly reduce cardiovascular-associated mortality. There were certain limitations to this meta-analysis. First, the heterogeneity of the meta-analysis was strong, with undefined reasons. Second, the sample size was relatively small, and future studies involving larger cohorts are warranted to further assess the effects of bedtime antihypertensive medication on minimizing morning BP surges.
\end{abstract}

Keywords: Hypertension; antihypertensive drugs; bedtime; morning blood pressure surge; meta-analysis

Submitted Apr 29, 2021. Accepted for publication Jun 18, 2021.

doi: 10.21037/apm-21-1405

View this article at: https://dx.doi.org/10.21037/apm-21-1405

\section{Introduction}

Hypertension is a serious condition that results in severe medical and economical burden worldwide. A recent report, the PURE study, suggested that hypertension is the greatest risk factor for cardiovascular events, contributing to $22.3 \%$ of cardiovascular episodes, and the morning peak blood pressure (BP) is an especially important factor (1). A cohort study showed that a $1 \mathrm{mmHg}$ increase in morning $\mathrm{BP}$ was 
associated with a $2.1 \%$ increase in the risk of cardiovascularassociated death $(2,3)$. Administration of antihypertensive drugs before bedtime has been developed as a treatment strategy for BP management. In fact, some studies have demonstrated that compared with morning dosing, bedtime dosing reduced cardiovascular-related deaths by almost half $(4,5)$. Numerous studies have examined the effects of taking antihypertensive medication before going to bed. These reports demonstrated that compared to drug administration at bedtime, administration of the medication during the daytime resulted in a significant increase in the 24-hour mean systolic blood pressure/diastolic blood pressure (SBP/ DBP) in patients, especially at night, and thus, the incidence of non-dipping BP was reduced (6-8). Other studies have confirmed that taking antihypertensive drugs at bedtime exerted a beneficial effect on the 24-hour BP, especially at night. However, currently, there is no consensus on the morning peak BP-lowering effect of this strategy. Therefore, this meta-analysis was conducted to assess the influence of bedtime antihypertensive drugs on morning BP levels. We present the following article in accordance with the PRISMA reporting checklist (available at https://dx.doi. org/10.21037/apm-21-1405).

\section{Methods}

\section{Search strategy}

This meta-analysis was conducted following the PRISMA guidelines (9). The PubMed, Embase, Cochrane, and ISI Web of Science databases were searched from January 1980 to December 2019 without language restrictions. Two researchers independently carried out these searches and any disagreements were resolved by discussion. The search strategy adopted in this study (10).

\section{Selection criteria}

The following selection criteria were applied to the literature: (I) the study included adult patients with hypertension as diagnosed by SBP $\geq 140 \mathrm{mmHg}$ or DBP $\geq 90 \mathrm{mmHg}$ (11); (II) experimental trials of antihypertensive drugs for at least 6 weeks (including calcium channel blockers, angiotensin-converting enzyme inhibitors, angiotensin receptor blockers, beta-blockers, diuretics, and alpha-blockers); (III) patients in the experimental group were administered one or more antihypertensive drugs before going to bed (from 5:00 pm to 12:00 midnight), and patients in the control group were matched with the same medication and dose, but administered during the daytime (from 6:00 am to 12:00 noon); and (IV) the pre- and posttreatment SBP and DBP of each patient were measured by Ambulatory Blood Pressure Monitoring (ABPM), which is the gold standard for BP measurement and the most cost-effective strategy for diagnosing hypertension and evaluating the true BP levels (12).

\section{Data extraction}

Basic data were collated from the included literature, including authors, year of publication, number of samples, interventions (grouping, drugs, intervention duration), and study design.

\section{Methodological assessment}

The methodological quality was independently assessed by two authors using the bias risk tool according to the Cochrane Handbook 5.1.0.

\section{Subgroup analysis}

Heterogeneity between studies was analyzed and the literature was classified according to the different sources of heterogeneity.

\section{Risk of bias}

The risk of bias was calculated according to the Cochrane Handbook for systematic review of interventions (13). The following six criteria were used: (I) the bias of selection (random-sequence generation and allocation concealment); (II) the bias of performance (blinding of participants and personnel); (III) the bias of detection (blinding of outcome assessment); (IV) the bias of attrition (incomplete outcome data); (V) the bias of reporting (selective reporting); and (VI) other bias. The three potential bias judgments were low, high, and unclear risk.

\section{Statistical analysis}

The Review Manager (RevMan, Version 5.1, Copenhagen: The Nordic Cochrane Centre, The Cochrane Collaboration, 2011) was used to analyze the data of all included trials. Meta-analysis was based on generalized inverse variance. 


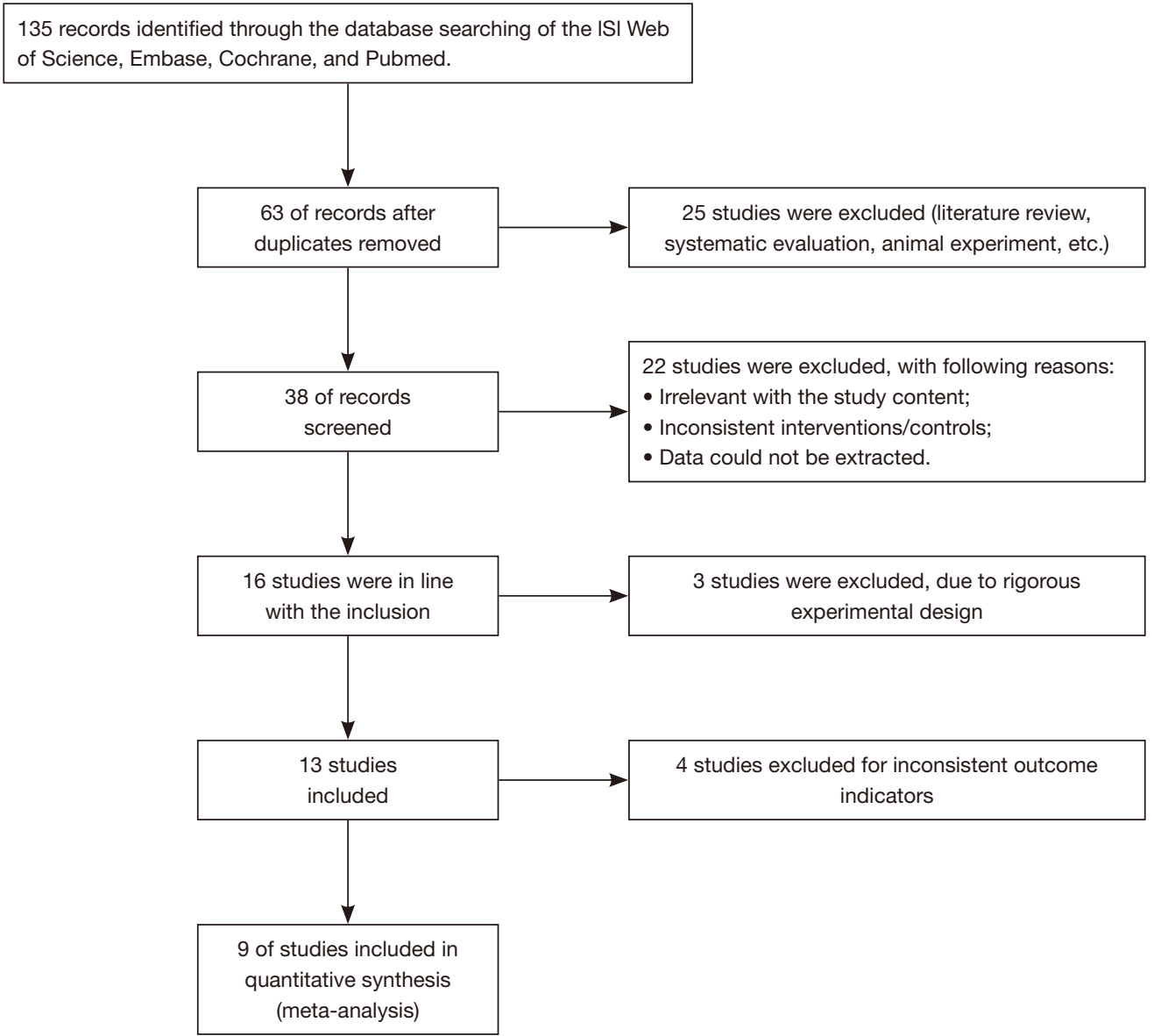

Figure $1 \mathrm{~A}$ flow chart showing the literature selection process.

\section{Statistical heterogeneity and sensitivity analysis}

Statistical heterogeneity was assessed using the $\mathrm{I}^{2}$ and $\mathrm{Q}$ test statistics, which were defined by $\mathrm{I}^{2}$ values of $25 \%, 50 \%$, and $75 \%$. Sensitivity analysis was performed to ensure that the included literature had no significant effect on the stability of the study.

\section{Bias test}

Funnel plots and Begger's tests were used to evaluate publication bias.

\section{Results}

\section{Literature selection}

A total of 135 articles were identified in the database search, of which, 72 studies were removed due to duplication, and
25 articles were excluded as they were literature reviews, systematic evaluations, protocols, case reports, or animal experiments. A further 22 studies were excluded due to irrelevant study content, inconsistent interventions/controls, or data could not be obtained. A total of 3 studies were excluded because of rigorous experimental designs, and 4 studies with inconsistent outcome indicators were removed. Finally, 9 studies, including 10,157 cases, were included in this quantitative synthesis (meta-analysis; Figure 1).

\section{Risk of bias assessment}

A total of 9 clinical trials (14-22) were included in this metaanalysis. All trials reported random sequence generation. None of the trials provided a detailed description of the allocation concealment. All included literature reported complete outcomes, without selective reporting and none of the trials reported bias (Figure 2). 


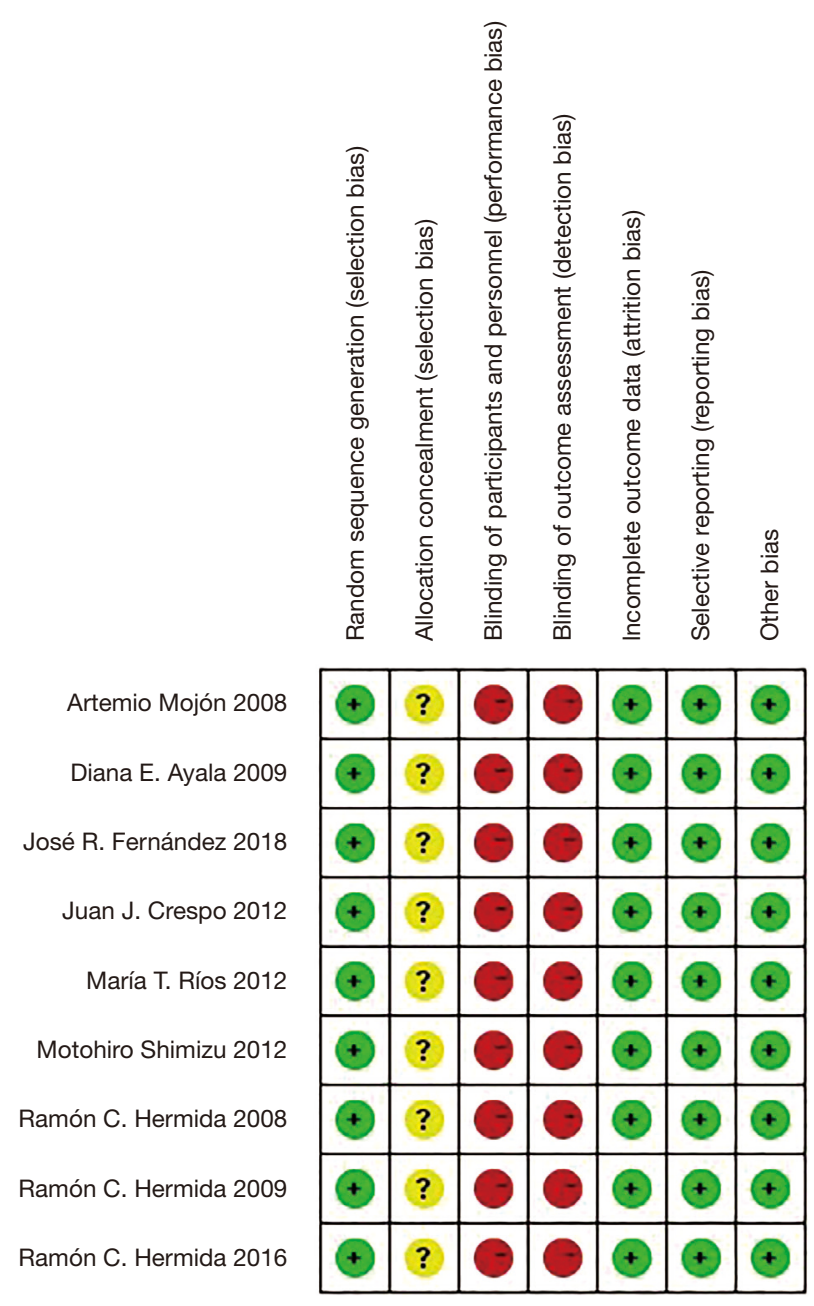

Figure 2 Risk of bias assessment. The three potential bias judgments were low risk, high risk, and unclear risk. Red represents high risk, green represents low risk, and yellow represents unclear risk.

\section{A meta-analysis of the morning SBP}

A total of 8 trials reported two outcomes, that being the SBP and the DBP from the morning BP measurements. One trial (20) only reported the SBP from the morning BP measurements.

From the 9 clinical trials included in this meta-analysis, there was a total of 10,157 hypertensive individuals. Due to the strong heterogeneity $\left(\mathrm{I}^{2}=75 \%>50 \%\right.$, and $\mathrm{Q}$ test $>0.1$ ), the random effects model was used. The results demonstrated that bedtime administration of antihypertensive drugs reduced morning SBP by $1.17 \mathrm{mmHg}$ [95\% confidence interval (CI): -2.49 to 0.14 ;
$\mathrm{P}=0.08]$ compared with drug administration during the daytime (Figure 3).

Sensitivity analysis on the 9 included trials showed that none had a significant impact on the stability, and the above random effects were used for an effective combination (Figure 4).

The funnel chart of the 9 included studies in the metaanalysis of SBP was symmetrical (Figure 5) and the bias test was carried out at the same time. The Begg's test showed that $\mathrm{P}=0.297>0.05$, suggesting that there was no publication bias in the included literature.

\section{A meta-analysis of the DBP from the morning BP measurements}

A total of 9,903 hypertensive individuals from 8 clinical trials were included in this meta-analysis. Due to the strong heterogeneity $\left(\mathrm{I}^{2}=79 \%>50 \%\right.$, and $\mathrm{Q}$ test $\left.>0.1\right)$, a random effects model was used. The results demonstrated that bedtime administration of antihypertensive drugs reduced morning DBP by $0.95 \mathrm{mmHg}$ (95\% CI: -2.03 to $0.13 ; \mathrm{P}=0.08)$ compared with patients in the daytime drug administration group (Figure 6).

Sensitivity analysis on these 8 trials showed that none had a significant impact on stability, and the above random effects were used for an effective combination (Figure 7).

The funnel chart of the included studies was symmetrical (Figure 8) and the bias test was performed at the same time. The Begg's test showed that $\mathrm{P}=0.805>0.05$, suggesting that there was no publication bias in the included literature.

\section{Discussion}

The random effects model demonstrated that bedtime administration of antihypertensive drugs reduced morning SBP in patients by $1.17 \mathrm{mmHg}$ (95\% CI: -2.47 to 0.37 ; $\mathrm{P}=0.08)$ and reduced morning DBP by $0.95 \mathrm{mmHg}(95 \%$ CI: -2.03 to $0.13 ; \mathrm{P}=0.08)$ compared to patients who received medication during the daytime. Although the results were not statistically significant, administration of antihypertensive drugs at bedtime appeared to have reduced morning BP surges.

The incidence of cardiovascular events, such as myocardial infarction, sudden death, and stroke, in hypertensive individuals is highest in the early hours after waking $(23,24)$. Studies have shown that an increase in morning $\mathrm{BP}$ by $1 \mathrm{mmHg}$ is associated with a $2.1 \%$ 


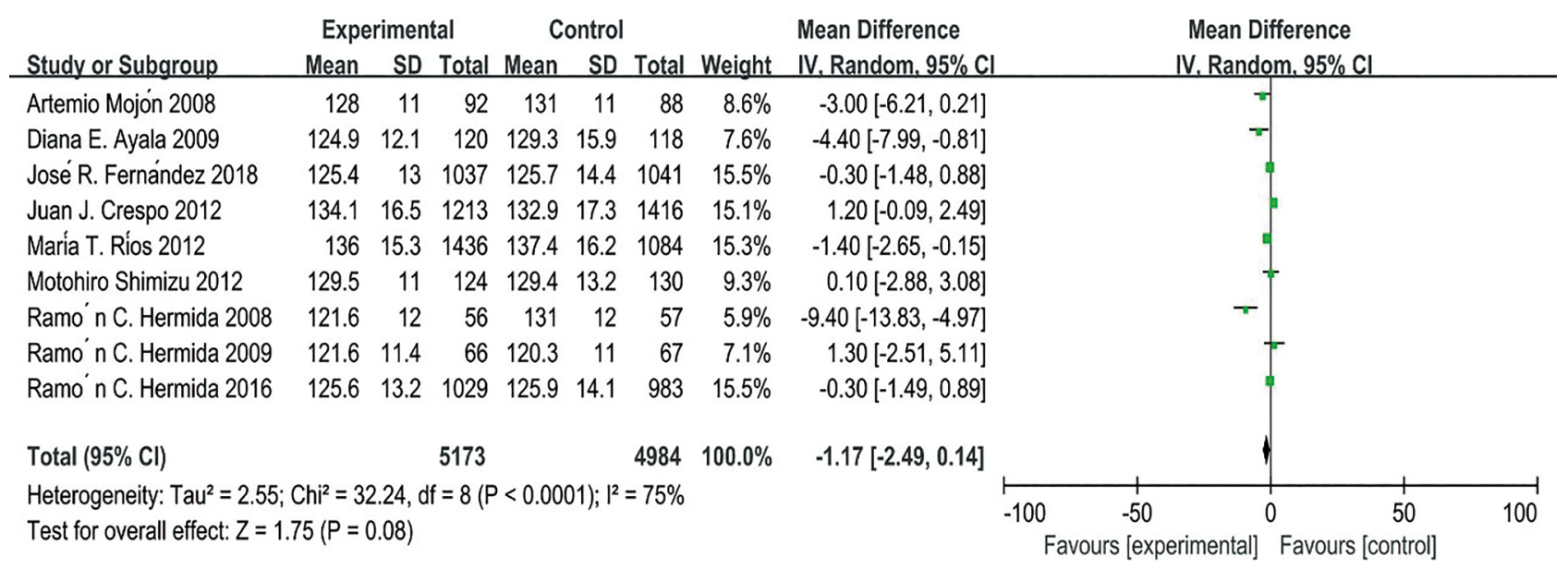

Figure 3 Statistical heterogeneity.

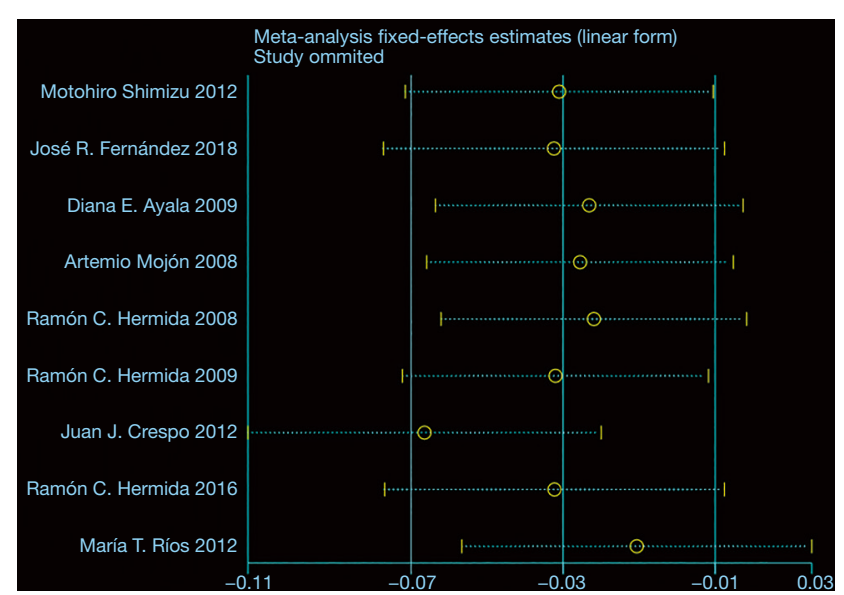

Figure 4 Sensitivity analysis.

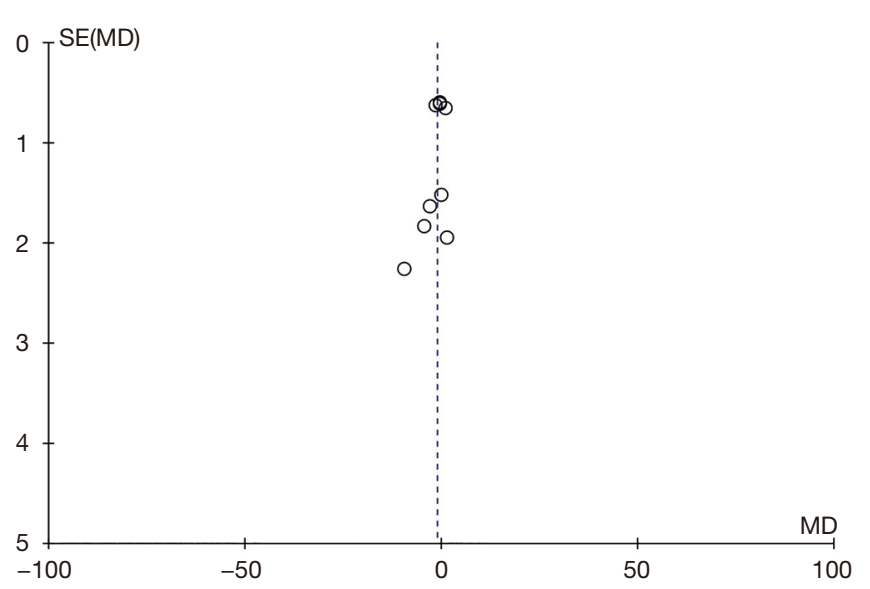

Figure 5 Bias test.

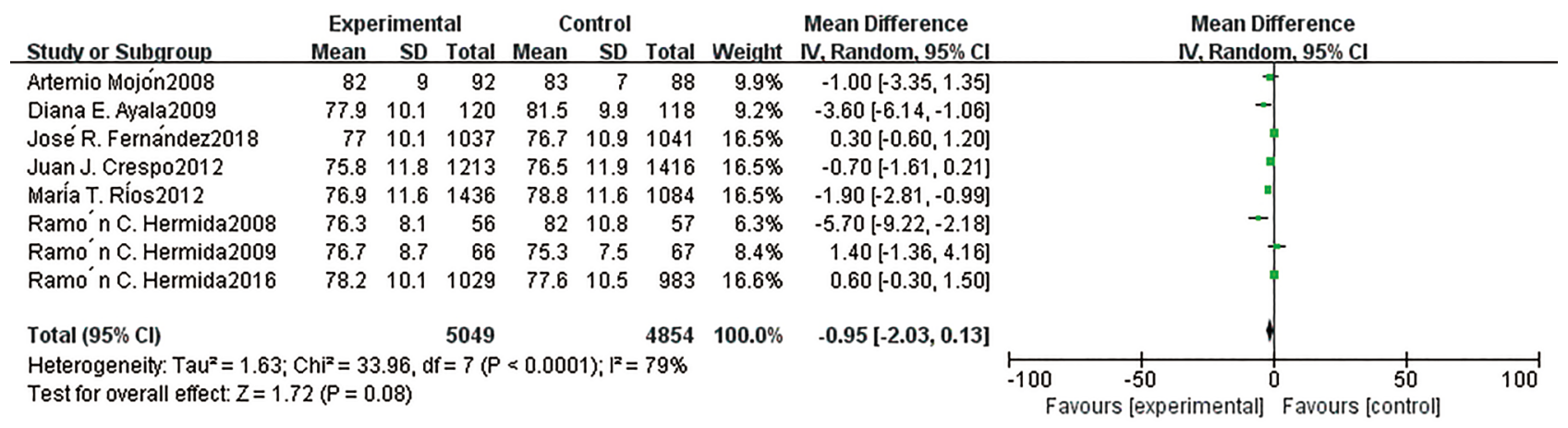

Figure 6 Statistical heterogeneity. 


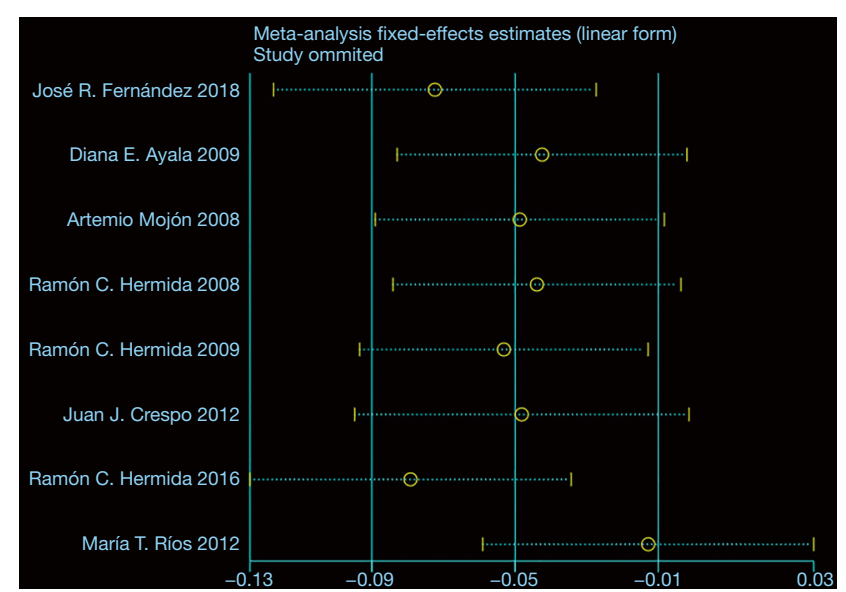

Figure 7 Sensitivity analysis.

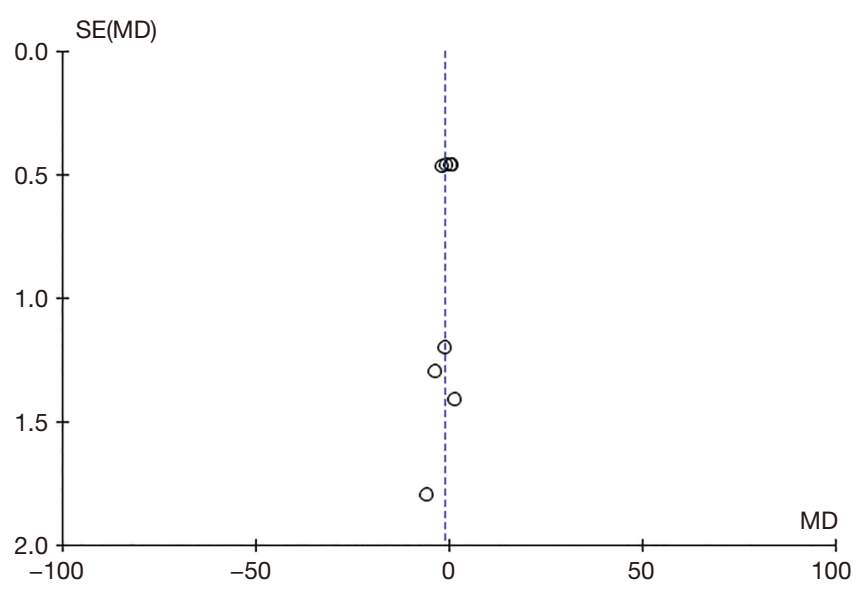

Figure 8 Bias test.

increase in the risk of cardiovascular-related deaths $(2,3)$. Increasingly, investigations have demonstrated that the elevation in morning BP is an important factor in cardiovascular events, renal function damage, and stroke (25-27). Clinical guidelines suggest that long-term use of 24-hour BP stabilizing antihypertensive drugs can control the large fluctuations of $\mathrm{BP}$ in the mornings and reduce the early peak BP rises caused by the failure to take drugs on time or a lack of medical care. Indeed, bedtime administration of nifedipine has been shown to significantly reduced the morning BP surge, which is a significant risk factor for stroke (14). At present, most patients with hypertension, especially those with primary (grade 2) or secondary hypertension, require the use of combination therapy to achieve satisfactory BP control (28). A report examining the effects of combination therapy on the antihypertensive efficacy of different administration time showed that compared with twice or multiple administration, once daily administration had the highest patient compliance. Hypertension is a chronic disease and most patients will require life-long medication. There is increasing evidence that compliance with antihypertensive drugs of $80 \%$ or more can improve $\mathrm{BP}$ control and reduce the risk of BP complications (29). The traditional regimen of antihypertensive drugs involves administration in the morning, usually with breakfast, which can reduce the rate of omission. An optimal once-a-day treatment of hypertension can not only reduce BP, but can also facilitate the normalization of the circadian rhythm of BP $(30,31)$. Studies by Farah others (6) have found that changing the timing of drug administration to bedtime can improve BP control and avoid non-spoon rhythm without increasing drug dosage.

This present study summarized and analyzed 9 RCTs, including 10,157 cases of hypertensive individuals. The data suggested that bedtime administration of antihypertensive drugs may be more beneficial compared to drug administration during daytime. The differences in the amplitude of hypotension was only $1.17 \mathrm{mmHg}$ in the morning SBP and $0.95 \mathrm{mmHg}$ in the morning DBP. However, studies have shown that a $1 \mathrm{mmHg}$ change was sufficient to reduce the risk of cardiovascular-related deaths by $2.1 \%$. Therefore, changing the time of taking antihypertensive medications may significantly reduce cardiovascular-associated mortality. Furthermore, bedtime administration of antihypertensive medication may improve patient compliance as administration of other commonly used cardiovascular drugs, such as statins, are recommended before bedtime. Bedtime administration also provides protection against hypertension in target organs at night. Some reports have suggested that as a result of social aging, many elderly people live alone and have adapted to a lifestyle of early exercise, and these patients tend to be affected by morning BP surges. However, this is controversial. Others believe that a sharp drop in BP at night will adversely affect organ blood supply. Zeng and colleagues (32) examined a group of patients who were administered a single tablet containing $5 \mathrm{mg}$ amlodipine and $20 \mathrm{mg}$ atorvastatin at bedtime $(10 \mathrm{pm})$, and another group of patients who were 
administered $5 \mathrm{mg}$ amlodipine and $20 \mathrm{mg}$ atorvastatin as separate tablets in the morning at $7 \mathrm{am}$. Although there was no significant difference in the adverse reactions between the two groups, the compliance of patients given the single pill was significantly better than that of the patients taking the two drugs as two separate tablets. The study showed that taking antihypertensive drugs before going to bed can be more effective at controlling morning BP fluctuations. In addition, the antihypertensive drugs that are widely used in the clinics tend to have a short half-life and action time, and thus if administered in the morning, the drugs may not provide complete 24-hour coverage, especially by early next morning. Therefore, taking antihypertensive drugs before going to bed can reduce the morning $\mathrm{BP}$, reduce the incidence of cardiovascular events, and improve the compliance of patients.

There were certain limitations to this meta-analysis. First, the heterogeneity of the meta-analysis was strong, with undefined reasons. Second, the sample size was relatively small, and future studies involving larger cohorts are warranted to further assess the effects of bedtime antihypertensive medication on minimizing morning $\mathrm{BP}$ surges.

\section{Conclusions}

Although there was no statistical significance, bedtime administration of antihypertensive medication tended to reduce morning BP surges, and thus, this treatment regimen may reduce the risk of cardiovascular events in patients with hypertension.

\section{Acknowledgments}

Funding: None.

\section{Footnote}

Reporting Checklist: The authors have completed the PRISMA reporting checklist. Available at https://dx.doi. org/10.21037/apm-21-1405

Conflicts of Interest: All authors have completed the ICMJE uniform disclosure form (available at https://dx.doi. org/10.21037/apm-21-1405). The authors have no conflicts of interest to declare.
Etbical Statement: The authors are accountable for all aspects of the work in ensuring that questions related to the accuracy or integrity of any part of the work are appropriately investigated and resolved.

Open Access Statement: This is an Open Access article distributed in accordance with the Creative Commons Attribution-NonCommercial-NoDerivs 4.0 International License (CC BY-NC-ND 4.0), which permits the noncommercial replication and distribution of the article with the strict proviso that no changes or edits are made and the original work is properly cited (including links to both the formal publication through the relevant DOI and the license). See: https://creativecommons.org/licenses/by-nc-nd/4.0/.

\section{References}

1. Yusuf S, Joseph P, Rangarajan S, et al. Modifiable risk factors, cardiovascular disease, and mortality in 155722 individuals from 21 high-income, middle-income, and low-income countries (PURE): a prospective cohort study. Lancet 2020;395:795-808.

2. Li Y, Thijs L, Hansen TW, et al. Prognostic value of the morning blood pressure surge in 5645 subjects from 8 populations. Hypertension 2010;55:1040-8.

3. Kario K. Perfect 24-h management of hypertension: clinical relevance and perspectives. J Hum Hypertens 2017;31:231-43.

4. Mayor S. Taking antihypertensives at bedtime nearly halves cardiovascular deaths when compared with morning dosing, study finds. BMJ 2019;367:16173.

5. Hermida RC, Ayala DE, Smolensky MH, et al. Chronotherapy with conventional blood pressure medications improves management of hypertension and reduces cardiovascular and stroke risks. Hypertens Res 2016;39:277-92.

6. Farah R, Makhoul N, Arraf Z, et al. Switching therapy to bedtime for uncontrolled hypertension with a nondipping pattern: a prospective randomized-controlled study. Blood Press Monit 2013;18:227-31.

7. Hermida RC, Ayala DE, Fontao MJ, et al. Administrationtime-dependent effects of spirapril on ambulatory blood pressure in uncomplicated essential hypertension. Chronobiol Int 2010;27:560-74.

8. Rossen NB, Knudsen ST, Fleischer J, et al. Targeting nocturnal hypertension in type 2 diabetes mellitus. 
Hypertension 2014;64:1080-7.

9. Liberati A, Altman DG, Tetzlaff J, et al. The PRISMA statement for reporting systematic reviews and metaanalyses of studies that evaluate health care interventions: explanation and elaboration. J Clin Epidemiol 2009;62:e1-34.

10. Zhang P, Jin MY, Song XY, et al. Comparison of the antihypertensive efficacy of morning and bedtime dosing on reducing morning blood pressure surge: A protocol for systemic review and meta-analysis. Medicine (Baltimore) 2021;100:e24127.

11. McCormack T, Boffa RJ, Jones NR, et al. The 2018 ESC/ESH hypertension guideline and the 2019 NICE hypertension guideline, how and why they differ. Eur Heart J 2019;40:3456-8.

12. Gorostidi M, Vinyoles E, Banegas JR, et al. Prevalence of white-coat and masked hypertension in national and international registries. Hypertens Res 2015;38:1-7.

13. Xing $M$, Yan X, Sun X, et al. Fire needle therapy for moderate-severe acne: A PRISMA systematic review and meta-analysis of randomized controlled trials. Complement Ther Med 2019;44:253-60.

14. Hermida RC, Ayala DE, Mojón A, et al. Chronotherapy with nifedipine GITS in hypertensive patients: improved efficacy and safety with bedtime dosing. Am J Hypertens 2008;21:948-54.

15. Hermida RC, Ayala DE, Mojón A, et al. Reduction of morning blood pressure surge after treatment with nifedipine GITS at bedtime, but not upon awakening, in essential hypertension. Blood Press Monit 2009;14:152-9.

16. Hermida RC, Ayala DE, Mojón A, et al. Comparison of the effects on ambulatory blood pressure of awakening versus bedtime administration of torasemide in essential hypertension. Chronobiol Int 2008;25:950-70.

17. Hermida RC, Ayala DE, Mojón A, et al. Risk of incident chronic kidney disease is better reduced by bedtime than upon-awakening ingestion of hypertension medications. Hypertens Res 2018;41:342-53.

18. Crespo JJ, Piñeiro L, Otero A, et al. Administrationtime-dependent effects of hypertension treatment on ambulatory blood pressure in patients with chronic kidney disease. Chronobiol Int 2013;30:159-75.

19. Hermida RC, Ríos MT, Crespo JJ, et al. Treatment-time regimen of hypertension medications significantly affects ambulatory blood pressure and clinical characteristics of patients with resistant hypertension. Chronobiol Int 2013;30:192-206.
20. Shimizu M, Ishikawa J, Yano Y, et al. Association between asleep blood pressure and brain natriuretic peptide during antihypertensive treatment: the Japan Morning SurgeTarget Organ Protection (J-TOP) study. J Hypertens 2012;30:1015-21.

21. Hermida RC, Ayala DE, Chayan L, et al. Administrationtime-dependent effects of olmesartan on the ambulatory blood pressure of essential hypertension patients. Chronobiol Int 2009;26:61-79.

22. Hermida RC, Ayala DE, Mojón A, et al. Bedtime ingestion of hypertension medications reduces the risk of new-onset type 2 diabetes: a randomised controlled trial. Diabetologia 2016;59:255-65.

23. Kario K, Yano Y, Matsuo T, et al. Additional impact of morning haemostatic risk factors and morning blood pressure surge on stroke risk in older Japanese hypertensive patients. Eur Heart J 2011;32:574-80.

24. Marfella R, Esposito K, Gualdiero P, et al. Morning blood pressure surge and the risk of stroke. Circulation 2003;108:e110-1; author reply e110-1.

25. Booth JN 3rd, Jaeger BC, Huang L, et al. Morning Blood Pressure Surge and Cardiovascular Disease Events and All-Cause Mortality in Blacks: The Jackson Heart Study. Hypertension 2020;75:835-43.

26. Turak O, Afsar B, Siriopol D, et al. Morning Blood Pressure Surge as a Predictor of Development of Chronic Kidney Disease. J Clin Hypertens (Greenwich) 2016;18:444-8.

27. Hoshide S, Yano Y, Haimoto H, et al. Morning and Evening Home Blood Pressure and Risks of Incident Stroke and Coronary Artery Disease in the Japanese General Practice Population: The Japan Morning SurgeHome Blood Pressure Study. Hypertension 2016;68:54-61.

28. Neldam S, Dahlöf B, Oigman W, et al. Early combination therapy with telmisartan plus amlodipine for rapid achievement of blood pressure goals. Int J Clin Pract 2013;67:843-52.

29. Flack JM, Nasser SA. Benefits of once-daily therapies in the treatment of hypertension. Vasc Health Risk Manag 2011;7:777-87.

30. Mochel JP, Fink M, Bon C, et al. Influence of feeding schedules on the chronobiology of renin activity, urinary electrolytes and blood pressure in dogs. Chronobiol Int 2014;31:715-30.

31. Huangfu W, Duan P, Xiang D, et al. Administration timedependent effects of combination therapy on ambulatory blood pressure in hypertensive subjects. Int J Clin Exp 
Med 2015;8:19156-61.

32. Zeng R, Wang M, Zhang L. Is Time an Important Problem in Management of Hypertension and Hypercholesterolemia by Using an Amlodipine-
Atorvastatin Single Pill Combination? Med Sci Monit 2016;22:2648-55.

(English Language Editor: J. Teoh)

Cite this article as: Jiang $\mathrm{H}, \mathrm{Yu} \mathrm{Z}$, Liu J, Zhang W. Bedtime administration of antihypertensive medication can reduce morning blood pressure surges in hypertensive patients: a metaanalysis. Ann Palliat Med 2021;10(6):6841-6849. doi: 10.21037/ apm-21-1405 